\title{
Jardín y paisaje en la obra poética (1967-2018) de Guillermo Carnero
}

\author{
Guillermo Carnero \\ Universidad de Valencia
}

Título: Jardín y paisaje en la obra poética (19672018) de Guillermo Carnero.

Resumen: El motivo del jardín ocupa un lugar destacado en la obra lírica de Guillermo Carnero. En el presente artículo el poeta y catedrático valenciano pasa revista al tratamiento del jardín en su poesía y reflexiona sobre su evolución.

Palabras clave: jardín, motivo literario y artístico, paisaje, Guillermo Carnero.

Fecha de recepción: 19/4/2021.

Fecha de aceptación: 27/4/2021.
Title: Garden and Landscape in Guillermo Carnero's Poetry (1967-2018).

Abstract: Bhe garden motif occupies a prominent place in Guillermo Carnero's lyrical work. In this article, the Valencian poet and professor reviews the treatment of the landscape and the garden in his poetry and reflects on its evolution.

Key words: Garden, Literary and Artistic Motif, Landscape, Guillermo Carnero.

Date of Receipt: 19/4/2021.

Date of Approval: 27/4/2021.

En mi poesía hay dos épocas bien diferenciadas, separadas por casi una década y seguidas, tras una pausa de ocho ańos, por un nuevo par de libros. La primera incluye los publicados entre 1967 y 1990, reunidos en el volumen Dibujo de la Muerte. Obra poética, que ha tenido dos ediciones: la de 1998 y la de $2010^{1}$. La segunda la integran los aparecidos entre 1999 y 2009: Verano Inglés, Espejo de Gran Niebla, Fuente de Médicis y Cuatro Noches Romanas, reunidos en 2020 dentro del volumen Jardín concluso (Poesía 1999-2009)2. Finalmente, en 2017 he publicado Regiones devastadas, y en 2018 Carta florentina, que, respectivamente, y

1 Guillermo Carnero, Dibujo de la muerte. Obra poética, ed. Ignacio Javier López, Madrid, Cátedra, 1998 y 2010. Antes aparecieron, con estudio preliminar de Carlos Bousoño y excluido el libro de 1990, bajo el título de Ensayo de una teoría de la visión, Madrid, Hiperión, 1979 y 1983 (1ª y 2a edición).

2 Guillermo Carnero, Jardín concluso (Poesía 1999-2009), ed. Élide Pittarello, Madrid, Cátedra, 2020. 
en términos generales, forman parte de la primera época y también de la segunda ${ }^{3}$.

Este estudio se deriva de una primera versión del año 2000 que concierne a la primera de esas épocas ${ }^{4}$. Fue revisado con adición de lo tocante a la segunda a sugerencia del profesor Santiago Fortuño (Universidad de Castellón), donde lo expuse, abreviado como conferencia, durante el verano del año 20165. Reviso ahora la revisión, a petición del profesor Jesús Ponce Cárdenas, tomando en consideración los libros de 2017 y $2018^{6}$.

En la primera versión de este texto escribí algo que sigue siendo cierto hoy: el hecho de tomar como objeto de mis reflexiones mi propia obra me ha sido muy útil para comprenderme a mí mismo; y por otra parte, en la medida en que haya aportado a la crítica algún enfoque relevante, habré también colaborado al mejor conocimiento de la poesía de mi tiempo, y de lo que lo que en ella significamos quienes hemos asumido un proyecto semejante de poeticidad.

Cuando afronté por primera vez la reflexión acerca de mi percepción de la naturaleza y el paisaje, recordé una anécdota de la infancia de Carlos Bousoño, que él mismo me contó. Su familia tenía al parecer amistad con

3 Guillermo Carnero, Regiones devastadas, Barcelona, Planeta/Fundación José Manuel Lara, colección Vandalia, 2017; y Carta florentina, Barcelona, Planeta/Fundación José Manuel Lara, colección Vandalia, 2018.

4 Guillermo Carnero, "Naturaleza y paisaje en Dibujo de la Muerte. Obra poética", Letra Internacional, 69 (2000), pp. 20-25; recogido en Poéticas y entrevistas 19702007, Málaga, Centro Cultural de la Generación del 27, 2008, pp. 85-92.

5 Guillermo Carnero, "Naturaleza y paisaje en mi obra poética (1967-2009)", en Poesia actual. Vivencies $i$ art, eds. Germá Colón, Rosa Agost \& Santiago Fortuño, Castellón, Universidad Jaime I, 2017, pp. 91-105.

6 Usaré las siguientes siglas para referirme a los distintos libros de los que consta esa obra hasta hoy: DM = Dibujo de la Muerte (1967 y 1971); SE = El Sueño de Escipión (1971); VF = Variaciones y figuras sobre un tema de La Bruyère (1974); PCDM (poemas del ciclo de Dibujo de la Muerte) y ETV (Ensayo de una teoría de la visión $)$ respectivamente los cuatro y tres poemas sueltos incluidos bajo ese rótulo desde Ensayo de una teoría de la Visión, primera recopilación de mis obras completas (Madrid, Hiperión, 1979); DI = Divisibilidad Indefinida (1990); VI = Verano Inglés (1999); EGN = Espejo de Gran Niebla (2002); FM=Fuente de Médicis (2006); CNR = Cuatro Noches Romanas (2009); $\mathrm{RD}=$ Regiones devastadas (2017); $\mathrm{CF}=$ Carta florentina (2018). 
Ígor Stravinsky, que pasaba de vez en cuando unos días de descanso con ellos en Asturias. A Carlitos le habían dicho que aquel señor había escrito una obra sobre la primavera, y yendo un día de primavera por los alrededores de Boal le dijo: "Mire usted, don Igor, qué bonitos los prados y las amapolas". Y don Igor, le contestó muy serio: "Niño, a mí la naturaleza no me interesa lo más mínimo”.

Pensé en un primer momento que a mí me ocurría lo mismo que a don Igor. Vivo en el Mediterráneo, donde el único paisaje que merezca tal nombre es el mar. En el Mediterráneo sólo me encuentro a gusto por la noche, y en lo demás prefiero el Atlántico, con sus tormentas y mareas, o el Mar del Norte, con sus icebergs y fiordos. Con todo, el Mediterráneo, aun siendo el grado cero como fuerza y elemento de la naturaleza (si bien todo lo contrario como ámbito de la clasicidad grecolatina), me ha deparado largas ensońaciones acerca del tiempo y de la escritura, en la cadencia de sus olas en miniatura y en su sucesión paralela de efímeras líneas blancas sobre una página oscura.

En cuanto a la tierra firme, mi paisaje preferido es el bosque nórdico, que se encuentra en contadas zonas de España. Si he de recordar cuál fue mi primera experiencia intensa del paisaje, ocurrió en las églogas de Garcilaso y la "Epístola del Paular” de Jovellanos. Y si pienso en un paisaje al que me gustaría retirarme, me vienen a la mente los óleos de $\mathrm{Hu}-$ bert Robert y de Santiago Rusińol, o los jardines de algunos palacetes del XVIII en Francia o Inglaterra. He llegado a pensar que no soy poeta del paisaje, y que he pasado más horas en los museos que en el campo. Pero eso hubiera sido dar por supuesto que naturaleza y paisaje sólo pueden entenderse en sentido agropecuario.

Los elementos del paisaje y la naturaleza pueden estar miméticamente presentes en un poema cuando denotan la experiencia directa de su referente real en estado y ámbito naturales; o bien puede tratarse, con intención también mimética, de la representación de lo natural en obras de arte, o de su extracción y situación en el ámbito humano con intención decorativa. Los elementos naturales son asimismo una cantera simbólica. Y por otra parte, la noción de experiencia es sumamente equívoca en poética y crítica. Habitualmente se entiende por experiencia el conjunto de hechos que ocurren en la vida cotidiana. Esos hechos son materia poética legítima cuando afectan a la reflexión emocional, 
pero el alcance de la experiencia no termina ahí: hay una experiencia de segundo grado o cultural, la que procede de la Historia, la Literatura o el Arte. Esas dos experiencias se encuentran natural y espontáneamente entrelazadas en el funcionamiento real del pensamiento y en la génesis, exploración y formulación de la emoción de una persona culta. Es idéntica la capacidad como detonador poético de un paisaje real a la de uno descrito en una obra literaria o representado en una obra de arte figurativo.

Es ley de la poesía contemporánea la consideración no realista de la naturaleza, viéndola como una cantera de símbolos bisémicos, aquellos que tienen, además de un referente real, connotaciones irracionales. Lo dijo Baudelaire en un conocido soneto de Las flores del Mal, y aludió a ello Verlaine en ese verso octavo de su "Arte poética" ("donde lo indeciso se une a lo preciso") que tanto repetía Juan Ramón como clave del auténtico Modernismo. El azul del cielo se convierte en símbolo de actitudes espirituales positivas en Martí, Darío, Lugones, Antonio Machado o Valle Inclán. En un artículo de 1898 ("Un poeta”, El Progreso) escribió Azorín: "Yo no sé si las cosas tienen alma, como pretenden los grandes artistas, Verlaine, Maeterlinck, Rodenbach; lo que sí sé es que hay instantes en la vida de todos los días, hay momentos en la prosa diaria en que es tal el estado de nuestro espíritu que hablan o cantan, gimen o lloran las cosas que nos rodean: un paisaje, una pintura, una lámpara, una estatua”. El paisaje ocupa el primer lugar entre esas cosas con alma, es decir, aquellas que nos permiten expresar de algún modo las "hondas realidades [espirituales] que carecen de nombre", según Antonio Machado en Los complementarios (“Sobre las imágenes en la lírica”).

El agua dulce es uno de los símbolos más universales del subconsciente colectivo. Cuando es clara y corriente, es el arroyo del que puede beberse sin peligro, la lluvia que hace germinar los campos y representa la vida; si es estancada y oscura, es la del lago que vela su profundidad y su contenido, y constituye un ámbito desconocido en el que pueden esconderse seres y fuerzas maravillosas o terribles; o la del pantano pútrido cuyos vapores ocultan la luz del sol y cuyo fondo engulle a quien lo atraviesa, y representa lo desconocido terrorífico, la muerte y el otro mundo. Pero los elementos acuáticos pueden también adquirir otros valores según su relación con el espacio y el tiempo. 
Además, el ser humano siempre se ha sentido vitalmente integrado en la naturaleza, y ha formulado esa integración en forma de jardín, que es un modelo en miniatura del mundo natural, tal como el hombre concibe su relación con él. Cuando esa relación no es más que utilitaria, sólo es el huerto del que obtiene parte de su dieta, o las plantas medicinales que destina a su farmacia. Cuando alcanza un grado superior, el jardín es la preciosa miniatura de un libro de horas, o el espacio real donde el hombre formula su lectura del mundo, su concepto de bienestar y felicidad y los fundamentos últimos de su espiritualidad. Si lo prefiere ordenado, regular y racional, como en la Francia del siglo XVIII, diseña superficies planas y parterres geométricos, recorta la vegetación y conceptualiza elementos y fuerzas naturales en fuentes con grupos escultóricos. Si lo prefiere irregular, imprevisible e instintivo, como en la Inglaterra del siglo XVIII, deja el terreno en su estado natural, la vegetación creciendo espontáneamente en bosques oscuros, senderos tortuosos, arroyos y cavernas. Si el hombre aspira a encontrarse cara a cara con su propio yo o con una realidad trascendente, se aparta del jardín, que lo ata excesivamente al ámbito sensorial, y se refugia en el yermo o en el desierto.

Así pues, naturaleza y paisaje pueden funcionar de modo muy diverso en la imaginación literaria:

1) Como referencia mimética al mundo real.

2) Como referencia mimética a su representación artística o a su uso decorativo, en el ámbito humano.

3) Como símbolo de actitudes existenciales o intelectuales.

4) Como referencia a la experiencia cultural, es decir, a su lectura en arte o literatura.

5) Elaborados en el microcosmos del jardín, tanto si éste procede de la experiencia directa como de la cultural.

Voy a aplicar ese esquema a mi obra poética, época por época. 
Primera ÉPOCA: I967-I990

\section{Referencias miméticas al paisaje y la naturaleza}

El paisaje descrito o aludido en sí mismo, como escenario en el que sucede algo que el poema recuerda, está prácticamente ausente. No encuentro más que un caso de referencia directa a la naturaleza: en "Atardecer en la pinacoteca” (DM), al querer realzar la sensación de reclusión y de apertura al vuelo de la imaginación y la memoria, en un museo, digo que la produce la debilidad de la luz crepuscular en los ventanales, o el sordo retumbar de la lluvia en la techumbre.

\section{Naturaleza representada en obras de arte, o convertida en material decorativo}

En "Primer día de verano..." (DM), las flores no se encuentran en su ambiente natural sino en jarrones, donde son renovadas una vez se marchitan, para representar la artificialidad y precariedad de la belleza que aportan al ámbito humano, en contraste con la renovación espontánea de la vida que tiene lugar en la naturaleza; en el mismo poema, el sol real ilumina, al atravesar unos visillos, un paisaje no real sino bordado, y que además representa una naturaleza convencional y literaria, la Arcadia, la región mítica de la felicidad en la Edad de Oro.

En "Brummel" (DM), el personaje poemático añade perfume a la flor marchita que lleva en la solapa, con el mismo significado; en "Watteau en Nogent-sur-Marne" (DM), las estaciones del año se mencionan como las figuras alegóricas que las representan en un reloj de autómatas, y el nogal que se cita es la madera de este árbol, empleada en la construcción de la peana. "Les charmes de la vie" (DM) menciona el bosque a través de sus dioses tutelares en la mitología clásica, y "Bacanales en Rímini...” (DM) cita el lugar ameno donde se bañan las ninfas.

En "Oscar Wilde en París" (DM) y en "Brummel” aparece el aroma de plantas y flores, pero convertido en esencia por arte del perfumista; el primero de esos poemas cita la madera taraceada —ensamblada formando conjuntos de colores diversos en muebles y objetos-, distintas flores y el perfume de las rosas como símbolo del cultivo solitario del espíritu 
y del refugio en la belleza al margen del mundo real. La madera de peral está también empleada en un reloj en "Capricho en Aranjuez", poema en el que las flores son adornos de hierro forjado. "Tras el cerco de Ímola" (DM) menciona juncos y sauces representados en un biombo. "Jardín inglés" (SE) cita la vegetación estilizada en bambalinas de teatro y en pintura mitológica. "Le Grand Jeu” (ETV) imagina el paisaje pintado en el interior de un diorama, una urna iluminada cuyo interior se contempla a través de una lente; en "Reloj de autómatas" (DI) tenemos otra vez las estaciones, y la tierra y el mar, convertidos en figuras alegóricas.

\section{Naturaleza y paisajes simbólicos}

En "Ávila” (DM), los ojos de la estatua yacente "conservan la ligera sombra azul de las raíces de la lluvia" porque, al ser muy joven el muerto representado en ella, parece tener aún un dejo de vida; vida es también la connotación del "monte lluvioso" en "Muerte en Venecia" (DM).

Quizás el poema más intensamente asociado al agua corriente, en esta primera época, sea "La hacedora de lluvia" (DI). En él se evoca un ritual mágico para obtener la lluvia entre los pueblos primitivos: sobre la tumba de un muerto por quemaduras se apaga con agua una rama ardiendo. En el poema, el cuerpo de una mujer se tiende sobre el de un hombre anímicamente muerto — simbólicamente quemado - para devolverle la vida.

El río de gran anchura aparece en "Castilla" (DM) como símbolo de la imposibilidad de traspasar los límites del propio yo por medio del lenguaje escrito; simboliza la incomunicación y convierte el texto en una reflexión sobre la poesía, un metapoema. En "Muerte en Venecia” (DM), la vitalidad del agua se contrapone a la inerte obra humana (quiosco, porcelanas), pero también es el agua, en tanto que espejo, símbolo de incomunicación: en ella se reflejan los dedos de quien desea tocar con ellos los del ser amado. En "Melancolía de Paul Scarron" (DM), un río paradójicamente inmóvil, identificado con el alabastro y el cristal, connota la indiferencia femenina. En "Lección del agua" (DI), dicha agua representa el tiempo en el que el yo se pierde, y el espejo, la escritura en que intenta conservarse engañosamente, ya que el agua es un espejo en movimiento, y el espejo un agua enmarcada. 
El mar es en su acepción más general un símbolo del viaje, de la aventura humana y del riesgo de emprenderla. Así funciona en "Ostende" (ETV), donde también utilizo la mansedumbre y certeza de la sucesión de las olas como símbolo de la previsibilidad del poema tras el trastorno emocional que produce una aventura amorosa. En "Le Grand Jeu" (ETV), el tópico paisaje costero de los lugares veraniegos se asocia a la falta de sorpresa que es consustancial a esas aventuras.

En "Variación I" (VF), el mar simboliza la vitalidad de la experiencia mientras es vivida, en contraste con la inmovilidad del recuerdo y de la memoria y de su traducción en discurso escrito, el cual se asocia al fango, es decir a las aguas estancadas.

En cuanto a la vegetación, en su sentido más general connota vitalidad: los álamos asociados al agua al comienzo de "Muerte en Venecia"; las palmeras de "Música para fuegos de artificio" (DI), símbolo de la renovación de la vida natural frente a las palmeras luminosas de los fuegos de artificio y de la otra pirotecnia que es escribir poesía. También puede representar lo contrario: los perfiles retorcidos de los olivos en "Ávila", tan retorcidos como el leño muerto convertido en pértiga de noria o las almenas de un castillo semiderruido.

El paisaje en sentido global — muchas veces sustituido por el horizonte - representa la vida del mundo natural, en contraste con los espacios artificiales creados por el hombre para obtener, a cambio de esa vida, protección y refinamiento, en "Pisa” y "Tras el cerco de Ímola” (DM). En "Concertato" (DM) la noche de verano representa la expansión de los sentidos y la acuidad del deseo. En las cuatro "Variaciones" (VF) el mundo natural representa la vitalidad de las sensaciones antes de ser disecadas en el recuerdo, la conceptualización y la escritura: véanse los ocho versos últimos de "Variación III".

Lo mismo la rosa, en "Mira el breve minuto de la rosa" (VF); así, en "Lección del páramo" (DI), el paisaje se considera en su espectáculo, por sobrio que sea, superior a su elaboración intelectual de cualquier índole. En "Fantasía de un amanecer de invierno" (DI), el amanecer trae, tras la noche y con la reaparición de formas y colores, el significado del paisaje, como las estaciones traen la renovación de la vida mientras recuerdo y escritura administran un bagaje muerto. 


\section{Naturaleza procedente del imaginario cultural}

En "Ávila" los pétalos, ramos y frutos son los esculpidos en el mármol del sepulcro del príncipe don Juan, hijo de los Reyes Católicos, en el convento de Santo Tomás. En "Atardecer en la pinacoteca", la laguna azul es la Estigia (la que debían cruzar las almas de los muertos camino del otro mundo, de acuerdo con las creencias de la Antigüedad clásica), y concretamente la Estigia pintada por Joaquín Patinir en el óleo que lleva ese nombre. En "Muerte en Venecia" las fresas, la laguna y el agua son símbolos de muerte por proceder de la novela del mismo título de Thomas Mann, en la que transmiten la peste. "Panorama desde la Tour Farnèse" (DM) recrea un paisaje literario que viene de La cartuja de Parma de Stendhal, además representado como una pintura de paisaje. "Boscoreale" (DM) menciona las acacias que caracterizan la pintura de Henri Rousseau, y "Sagrado Corazón y Santos..." (DM), las flores pintadas por Iácopo Guarana.

"El serenísimo príncipe Ludovico Manin" (DM) menciona al último dux de Venecia como símbolo de decadencia en el momento (1797) en que la Serenísima acaba su trayectoria secular de grandeza y arte al ser conquistada por Napoleón. El mar aparece en el poema en dos sentidos: primero, como el auxiliar fiel de la pasada gloria de Venecia, cuya economía estaba basada en el comercio marítimo y donde se celebraba anualmente la fiesta de la boda de la ciudad y el mar, arrojando el dux un anillo al agua desde la falúa llamada Bucentauro; segundo, como contraste entre el mar abierto, libre y en movimiento, y el mar de la ciudad y sus canales, "sudario inamovible" para el cadáver del esplendor perdido.

"El embarco para Cyterea" (DM) alude al óleo de Watteau del mismo título. La palabra "Cyterea" adquiere, escrita con "y", connotaciones arcaicas y relativas a la literatura de fines del siglo XIX que pretendo hacer visibles. Cyterea es una isla situada entre Creta y el Peloponeso, a la que, según la leyenda, fue a arribar Venus después de su nacimiento de la espuma del mar. Tenía en la Antigüedad un santuario dedicado a la diosa, al que acudían los peregrinos del Amor. Ese viaje simboliza la esperanza en que las penas de amor tengan remedio, y por encima de todo, la creencia en el significado redentor del amor, sin el cual la vida carece de sentido. La cita del Génesis que encabeza el poema, extraída de su contexto y despojada de su significa- 
do propio, viene a indicar que el amor eleva al ser humano a su mejor y más alta condición. Y como en el Génesis, esa elevación acaba siendo ilusoria y viene seguida de una degradación y un castigo. Tras la lectura del poema se percibe que la cita se ha introducido con intención irónica.

Lo que desde el primer momento me atrajo de esta pintura de Watteau fue su tristeza. Que la escena esté vista desde lejos me dio a entender que el pintor quería indicarnos que se autoexcluía del viaje, que carecía de las ilusiones y las esperanzas de los viajeros del Amor; y la falta de vitalidad y de alegría que parece pesar sobre los personajes, que se embarcan como movidos por un rito, una obligación social y cortesana, pero no una convicción vital. En resumen, siguiendo la contradicción que el cuadro parece poner de manifiesto a la vista de su contenido iconográfico, de la gestualidad y la exteriorización de la espiritualidad de sus personajes, inserté en el poema dos series paralelas de referencias, unas positivas y acordes con el supuesto asentimiento al significado del tema ("grifos dorados", "bronces", "juegos de música”, "brillante clamor", "gracias escondidas", "sabiduría vieja como el mundo", "lujo alegre y sabio"), otras negativas y negadoras de ese asentimiento ("triste nave", "espectacular monotonía”, "mar de ceniza", "estar solo").

La contradicción se resuelve en los versos finales, donde la voz de Watteau — que es, como desde el primer verso, la del poeta - confiesa haber realizado en el pasado el viaje marítimo con fe y esperanza, y que ambas han resultado defraudadas, no quedando en su opinión más justificación para el mantenimiento de la aparente creencia colectiva en la virtud de ese viaje que un ejercicio de voluntad que forma parte de las formas de relación cortés y cortesana entre las personas, una mentira a voces que nadie, sin embargo, declara abiertamente porque forma parte de las buenas formas y porque gracias a unas cuantas esperanzas, por muy infundadas que sean, y gracias al pacto colectivo que las sostiene, puede el hombre creer durante parte de su vida que estar vivo tiene sentido.

En "Primer día de verano", zarcillos, hojas y emparrados representan la vitalidad natural en contraste con la abulia y la decadencia física humanas, interpretando la novela El amante de Lady Chatterley de David Herbert Lawrence.

"Les charmes de la vie", poema basado también en un cuadro de Watteau, lo entiende como representación del deseo irrealizable, y con 
ese sentido introduce "el rastro de umbría verdura" producido por un río subterráneo que no consigue llegar a la superficie. Idéntica es la función de la naturaleza en "Tempestad", sobre un óleo de Giorgione donde la complementan la lanza de un soldado y una columna truncada.

La sucesión de las estaciones implica la renovación de la vida natural y la "proclamación de la primavera", con alusión a Botticelli, en "Panorama desde la Tour Farnèse", en contraste con el aislamiento y la incomunicación de la voz del poema, todo ello como reelaboración de La cartuja de Parma; primavera es también antítesis de la decadencia en el título de "El serenísimo príncipe Ludovico Manin”.

"Jardín inglés" introduce las estaciones representadas en los Libros de Horas medievales y renacentistas, y la primavera pintada por Palma el Viejo a comienzos del siglo XVI. "Piero della Francesca" (SE) menciona la "censura de la flora" como rasgo distintivo de este pintor, junto al hieratismo de sus figuras, para apostar por un tratamiento intelectual y metapoético de las emociones ${ }^{7}$, lo mismo que "Páestum" (VF); este poema plantea el contraste entre la luz mediterránea y el diseño geométrico del estilo dórico, inicios del intelectualismo del espíritu y la religión griegos, con la oscuridad y el terror que rodean a los dioses bárbaros ocultos en cavernas, para indicar el rechazo de la exhibición primitiva de las emociones en literatura. "Investigación de una doble metonimia" (SE) introduce el paisaje pintado por Giovanni Bellini en Las almas del Purgatorio; "Giovanni Battista Piranesi” (VF), los árboles dibujados en las imposibles construcciones de este grabador y arquitecto.

"Le Grand Jeu" (ETV) se abre con la cita de un manuscrito del siglo XV que describe un paisaje del Paraíso formado por papeles coloreados y pegados; "Ostende" (ETV) introduce el bosque de las narraciones artúricas en el que un caballero, de viaje o de caza, encuentra a una mujer irreal de la que se prenda y a la que sigue. "Divisibilidad indefinida" (DI) recrea el paisaje lunar hecho de guijarros y formas inorgánicas que caracteriza, como escenario de la desolación, la pintura surrealista de Yves Tanguy.

7 Véase "Un poema frío: Piero della Francesca", Ínsula, 774 (junio de 2011), pp. 44-45. 


\section{Naturaleza y paisaje elaborados como jardin}

Jardines y parques aparecen en Dibujo de la Muerte — "Muerte en Venecia", "Primer día de verano", "Les charmes de la vie", "Watteau en Nogent-sur-Marne", "Capricho en Aranjuez" - como símbolo del fracaso de la pretensión humana de sustituir por la belleza artificial la vitalidad primitiva de la naturaleza salvaje; especialmente en el último de los poemas citados, donde el jardín simboliza el lenguaje poético y convierte el texto en un metapoema.

"Jardín inglés" (SE) describe un jardín que simboliza la incomunicación y la frustración del deseo, en su vegetación amortecida por el invierno y en la inmovilidad de sus estatuas, tanto como las figuras de pastor y ninfa representadas en la veleta de "Los motivos del jardín" (DI). En "Variación IV" (VF), el jardín desierto representa la degradación de la experiencia en el recuerdo, lo mismo que las fuentes heladas en "Ostende", y el jardín de la memoria en "Música para fuegos de artificio" (DI).

SEGUNDA ÉPOCA: I 999-2009

\section{Referencias miméticas al paisaje y la naturaleza}

"Leicester Square" (VI) rememora una escena situada en la plaza londinense del mismo nombre. Se trata de un pequeño parque con parterres sembrados de césped, en los que crecen flores y hay plantados árboles donde anidan o entre los que revolotean pájaros, y asimismo una fuente y los clásicos buzones británicos de color rojo. Los parques londinenses, con raras excepciones, están a disposición del transeúnte para caminar a su través y tenderse en la hierba, gracias a lo cual el poema ha diseñado $\tan$ inconsciente como precisamente ese ambiente como un locus amoenus urbano, idéntico al tradicional si disculpamos la presencia de los buzones y consideramos que el fluir del agua en una fuente construida por el hombre es equiparable al libre discurrir de un arroyo entre guijarros y juncos. Ese lugar, real en la topografía londinense, puede así adquirir un significado adicional procedente de la tradición poética desde la Antigüedad clásica, gracias a su accesibilidad y al hecho de que en su espacio 
transcurra un episodio de comunicación y plenitud amorosa. Por otra parte, el poema está aludido, en el recuerdo de sus versos 13 y 14, al final de "Noche Primera" de Cuatro Noches Romanas.

El paisaje de "Amanecer" (VI), está descrito con el detalle y la prolijidad procedentes de la acuidad y autocomplacencia sensorial de quien, desde la cama, percibe unos olores e imagina otros que les están asociados (sexo, miel, hierba, hojas, leña, yute, pan, pastelería, cecina, cera), y que lo llevan a imaginar lo que hubiera visto si se hubiera asomado a la ventana de la habitación en que se encuentra; todo ello, por las sugerencias del olfato, ha de producirse en un ambiente rural. El paisaje implícito es el valle del curso bajo de un río con sus meandros y trigales; estamos en la época de la siega porque el tamo flota en el aire y se vislumbran los almiares, conformados alrededor de un palo hincado en la tierra, en cuyo extremo superior ondea un trozo de tela a modo de banderola, que significa perduración de la vida gracias a la tierra nutricia. También desde la cama, y en compañía, como en "Amanecer", se escribe "Noche de los vencejos" (VI): el griterío de los pájaros mientras vuelan en círculo al caer la noche evoca una arboleda circundante. El campo tras la lluvia se evoca en "How many moles?" y "Sweetie, why do snails...?" (VI los dos); el paisaje de la desembocadura del Támesis en "Greenwich banks" (VI). El del parque de Greenwich en "Retorno a Greenwich Park" (VI), tan real en el verano vivido como simbólico en el invierno imaginado en el recuerdo, y en el primer caso conteniendo asimismo elementos propios del locus amoenus.

\section{Naturaleza representada en obras de arte, o convertida en material deco- rativo}

Está prácticamente ausente en esta segunda época, descontando la mención de Cézanne en "Ficción de la palabra”, de Espejo de Gran Niebla.

\section{Naturaleza y paisaje simbólicos}

En “Ojos azules” (VI) la primavera, época de renovación de la naturaleza, se convierte en símbolo de la deseada iniciación del amor y la entrega en él. Es 
asimismo simbólica la primavera de "Campo de Mayo", con la ominosa referencia a la siega. Y lo es el desierto en "Composición viendo el lugar" (VI), escenario de una aridez que significa indiferencia y ausencia de implicación sensorial, lo opuesto a la selva tropical y la erupción volcánica.

En Espejo de Gran Niebla predomina el pensamiento sobre cualquier otra motivación, y en consecuencia paisaje y naturaleza, cuando aparecen, adquieren una significación preferentemente simbólica. El agua se convierte así, desde los primeros versos del primero de los cinco poemas que forman el libro, "Noche de la memoria", en símbolo de la percepción sensorial inherentemente transitoria: aquí la espuma de las olas sucesivas del mar durante la noche, equiparadas a líneas sucesivas de una escritura en blanco sobre papel negro. Al mismo tiempo, la marea alta, en el estuario (del Támesis), las empuja río arriba, y en sentido opuesto el fluir del río hacia el mar, de tal modo que el libro comienza como una orquestación de movimientos de avance y retroceso, en sentido vertical y horizontal, de la evanescencia de las percepciones sensoriales en litigio con su permanencia en la memoria y el pensamiento, todo ello en el ámbito del simbolismo acuático. Agua y lluvia mantienen su carácter simbólico en el segundo poema del libro, "El tiempo sumergido". La lluvia, agua retornada procedente del mar, trae consigo el rumor de los muchos ahogados que yacen en él, estaciones de la identidad debida a la realización sensorial, sumergida al desvanecerse su acuidad.

En el tercer poema, "Conciliación del daño", el pensamiento abstracto se equipara a la alta montańa, y la lluvia al olvido, en tanto que las aguas pluviales terminan en el mar. Por otra parte se recuerdan los arcaicos ritos de la fertilidad propios del pensamiento mágico: la mujer desnuda se convierte por ellos en estímulo de la renovación de la naturaleza. La elasticidad de su cuerpo se transmite a los vegetales, la suavidad de su piel a los frutos, la longitud de su cabello a la de las espigas; y la concesión de su desnudez gracias al amor es inspiración de vida y de escritura. Sin esa inspiración la inserción en la realidad y la capacidad de dar cuenta de ella se nos vedan como pepitas de oro escurridizas en el fluir de un río aurífero.

En el cuarto de los poemas, "Disolución del sueño", cumbres de montaña y estuarios de río son el espectáculo que simboliza la percepción abarcadora de la realidad que proviene del deleite de escuchar la voz de la mujer amada; y la redondez y curvatura de río, horizonte, brote tierno y 
fruto concuerdan con la del cuerpo femenino en tanto que obra maestra de la naturaleza.

\section{Naturaleza procedente del imaginario cultural}

"Lección de Música" (VI) utiliza la expresión analógica del pensamiento y la emoción debidos a una situación vivida, proyectándolos sobre un referente objetivo del imaginario cultural, en este caso una pintura o un grabado. Las dos primeras ediciones indicaban "Anónimo. Taller de Boucher". Se aludía, por lo tanto, a una manifestación del espíritu característico del Rococó dieciochesco —alegría de vivir, erotismo amable y risueño-, sin que esa alusión ocultara la experiencia personal trasparentemente aludida — una felación—, pero añadiéndole la aureola nostálgica de la hermosura y la delicadeza del siglo XVIII, mi época predilecta. El Museo Cognac-Jay de París exhibe una Leçon de Musique atribuida a Boucher, que no coincide con la descripción que da el poema, pues representa a un personaje tocando la mandolina delante de la estatua de una esfinge y junto a una dama que lee junto a una gran fuente, y tiene otra mandolina a sus pies. Entre ambos personajes no hay contacto alguno.

En Berger montrant à sa bergère à jouer de la flûte, óleo de Boucher de 1748 reproducido en grabado por René Gaillard con el título de L'Agréable leçon, un pastor acerca una flauta a los labios de una pastora, mientras le rodea el cuello con ambos brazos, y ella deja descansar la mano derecha en un bastón que él tiene entre las piernas, y que se apoya en su hombro. No pude ver esta obra, en grabado, hasta fines de 2001. Es la referencia más adecuada, finalmente identificada, a lo inicialmente inventado desde el conocimiento de la pintura erótica de la época, y posiblemente del recuerdo inconsciente del Boucher del Museo Cognac-Jay, que había visitado al menos una vez antes de escribir el poema.

"Beauregard" (VI) evoca la residencia de Anne de Pisseleu, amante del rey Francisco I de Francia (1494-1547). La descripción del entorno de Beauregard y Chambord, palacio construido por Francisco I en la ciudad de ese nombre, a quince kilómetros de Blois, está concebida como miniatura de un libro de horas de la época, tanto como el paisaje identificado al cuerpo femenino en "Noche del tacto". 
"Las Oréades, por Bouguereau” (VI) alude en su título al lienzo pintado por Bouguereau en 1902, representando a las ninfas tutelares de montes y bosques en la mitología clásica. El poema se refiere al desnudo y al escenario campestre característico de Boucher y otros pintores del Rococó, y evoca el óleo de Jean-Honoré Fragonard (1732-1806) titulado El columpio (Londres, Wallace Collection).

"Melusina" (VI) toma su nombre de una criatura femenina de las aguas dulces en el folclore céltico medieval, heredera de las límnades o ninfas de las aguas estancadas, en la mitología clásica. Según la leyenda, recogida en el Roman de Mélusine de Jean d'Arras (1392), estaba bajo la maldición de convertirse su cuerpo de cintura abajo, los sábados, en el de un dragón. Podía vivir una relación amorosa con un hombre, al que colmaba de felicidad y prosperidad, hasta que él descubría su monstruosidad, momento en que ella huía volando.

\section{Naturaleza y paisaje elaborados como jardín}

En "Al fin a vuestras manos he venido" (VI), el jardín tras la lluvia, con su olor a tierra mojada y los colores del arco iris, es símbolo del renacimiento en la plenitud sensorial gracias al amor; el abandono se identifica con la pérdida de esas emociones y sensaciones en "Me has quitado la paz de los jardines" (VI).

El jardín aparece más de una vez en Espejo de Gran Niebla, dada la densidad simbólica de este libro. En "El tiempo sumergido", el recinto del jardín mojado por la lluvia se convierte en imagen del ámbito de la memoria, habida cuenta del significado que la lluvia, dentro de la simbología del agua, adquiere en este libro. En "Conciliación del daño" se concreta como provincia específica de la memoria, la inocencia de la infancia y su pérdida. En "Disolución del sueño", de acuerdo con la tradición medieval, simboliza la castidad.

Fuente de Médicis debe su título a la fuente situada en el jardín del Luxemburgo de París, construida hacia 1630 por orden de María de Médicis, viuda del rey Enrique IV. Fue remodelada en el siglo XIX con adición en 1866 del grupo escultórico de Auguste Ottin (1811-1890) que representa a Acis y Galatea en el momento en que los sorprende Polifemo. 
El libro consta de un único diálogo entre el yo poético y Galatea, por lo cual resulta de la simbiosis entre el simbolismo del jardín y el del agua. El jardín se convierte ahora en escenario de la soledad culpable, de acuerdo con el motivo del parque abandonado, y el agua es agua estancada y sucia en la que se pudren flores y hojas muertas, agua que concede el olvido en la muerte a quien es conducido a ellas por mano de Galatea, con recuerdo, invirtiendo su significado de salvación, de Salmos 23.2: "Me llevará a reposar en verdes prados, me conducirá a aguas tranquilas, confortará mi alma [...] Aunque atraviese el valle sombrío de la muerte no temeré mal alguno".

En un jardín real y a la vez simbólico transcurre la "Noche segunda" de Cuatro Noches Romanas: el jardín de Villa Aldobrandini, no la de ese nombre radicada en Frascati, sino lo que queda de la situada entre Via Nazionale y via Panisperna, en Roma. Sus restos (degradados y abandonados cuando el poema fue concebido, más tarde restaurados) se interpretan, desde el imaginario cultural que connotan, como los de un jardín palaciego que fuera antańo escenario de una erudita corte de amor. El jardín se define en el poema como el arquetipo de naturaleza, que debe su belleza y perfección a la clausura y a la intervención del arte. Más adelante, las olas, las hojas de los árboles y el vuelo de las aves se mencionan como arquetipos de fugacidad.

\section{Dos libros FinAles (20I7 Y 20I8)}

En Regiones devastadas, pueden considerarse referencias al paisaje las que mencionan lugares arqueológicos ("Yacimiento", "Busto truncado de un desconocido", "Villa de un magistrado en Macedonia"), si bien el paisaje suele tener connotaciones que van más allá de la alusión o la descripción, empezando por las que aporta la arqueología misma: la obra humana en su fragilidad y degradación por la destrucción intencionada o el paso del tiempo. En otros casos, ese alcance se precisa y se diversifica. Si "Promontorio de Sunion" se refiere a un accidente geográfico de la costa griega, su significado incluye el del templo (en ruinas), y consiguientemente toda la carga simbólica del viaje por mar y su incertidumbre, y las interrogaciones acerca de la supuesta influencia divina en los destinos humanos. 
"Factoría de gárum..." alude a una realidad del urbanismo costero en la economía y el comercio del ámbito mediterráneo clásico, para confrontar su transustanciación en el legado homérico y virgiliano, y en el de los ideales de la cultura griega, con la mezquina realidad de la pesca y la salazón. "Estancia de Heliodoro" alude a espacios reales (los campos y ríos en los que se dispersaban las cenizas de las víctimas del Holocausto) contrapuestos al paisaje idealizado de los Libros de Horas y a la supuesta prevalencia de la justicia por obra de la no menos supuesta Providencia, todo ello en conexión con la obra de Rafael en las estancias vaticanas. La real laguna veneciana como lugar ambiguo de poder y muerte aparece en "Retrato del dux...". El hostil paisaje veraniego en que tuvo lugar la batalla de Alcazarquivir se convierte, en "Muerte del capitán...", en escenario de la aparición burlona de la mujer indiferente al amor y a la pleitesía intelectual y poética. Hasta aquí las referencias miméticas al paisaje y la naturaleza.

En "Ancianidad hermosa de Rodin" el horizonte montañoso es convertido por la erosión en el perfil de un cuerpo reclinado, operación que repiten, embellecidas por el amor, las manos deformes del viejo artista que conforma el mármol como cuerpo tendido y dormido.

La representación de la naturaleza en obras de arte, o su utilización como motivo en las llamadas artes decorativas, tiene en "Luis de Góngora, 1612" un ejemplo de gran polivalencia y densidad. La fecha alude al momento de composición de la Fábula de Polifemo y Galatea, cuando Góngora, ya al comienzo de la etapa final de su vida, concibe y escribe ese canto emocionado al encanto juvenil de Galatea. Su observación desencantada y ortopédica es que en la senectud la realidad (el Sol, el amanecer) es inalcanzable, y no cabe más que sustituirla por su transposición en arte (oro, jarrón de flores) o, últimamente, en el arte de la palabra, en el poema.

Es simbólico el árbol de "Árbol de otoño", en sus frutos podridos que a nadie atraen, frutos equiparados a las cinco letras de la palabra "árbol" y acaso a las de un indefinido nombre propio. Los colores y brillos que atraen al niño, en "Como un niño", son equívocos y peligrosos, por obra de una mirada inocente que, al ignorar el mal y carecer de malicia, equipara lo benéfico (mariposa, flor, ola) con lo dañino (serpiente, cuchillo).

La naturaleza representada en obras de arte que forman parte del imaginario cultural aparece en "Scripta manent" (la naturaleza escrita y per- 
sonificada con rasgos humanos por Virgilio), en "Susana en el baño..." (imaginada como un lugar ameno sólo insinuado por Tintoretto), en "Diana y ninfas..." (lugar ameno expreso aludido por Horacio).

Naturaleza y paisaje aparecen elaborados como jardín en "Atardecer en Roma”, donde el jardín de Villa Médici se convierte en caja de resonancia de la intimidad y del autoconocimiento; en "Para una tumba..." el cementerio napolitano de Staglieno se define como jardín invertido por la muerte, a través de la degradación y la suciedad de una de sus estatuas sepulcrales.

"Ruina artificial en un jardín" recuerda, a través del de Ermenonville, los artificiosos jardines dieciochescos diseñados como los acuñó la pintura contemporánea de ese género, y salpicados de falsas ruinas en aras del pintoresquismo, de la mostración de las etapas de la Historia y la fragilidad de toda obra humana, y en ocasiones alusivos a la transmisión a través de los siglos y las culturas de un supuesto saber ancestral identificado con la teosofía, la alquimia y la masonería. "Libro Primero de los Reyes" insinúa su localización en un jardín nocturno levemente iluminado, marco insuperable de la delicia de la desnudez.

"Vejez de Juan Bautista Tiépolo" ofrece articulados los cinco registros cuya presencia y alcance nos constan en Regiones devastadas: la constatación de la pérdida de contacto con la realidad física y moral, por obra de la idealización de la naturaleza (la fuente natural sustituida por la que mana en la gruta artificial de un ninfeo) y de la calidad del ser humano (los héroes de la clasicidad y su simbólica excelencia como paradigma de las virtudes del gobernante), con olvido del ineludible y degradante paso del tiempo (percibido en un reloj rococó) y del imperio del mal. El ninfeo implica siempre el entorno del jardín.

En Carta florentina se da la combinación más compleja de los elementos que venimos rastreando en estas páginas. El color y el sonido de cursos de agua, aves y arboledas ventosas (desde el comienzo: pp. 14, 17 y 21) se identifican como los detonadores de la memoria, y el horizonte marino crepuscular como un arco tensado para disparar, en la aproximación de la noche, la interrogación acerca del pasado, la cual se vuelve así portadora de vida al hincarse, como vara de Aarón, en la memoria fertilizada por el sonido nocturno (pp. 15, 16). El árbol, sin olvidar que las hojas de las distintas especies encarnan la variedad de la potencia evocadora que 
reside en el color, se vuelve a su vez un símbolo dual, representativo de las dos vías por las que la mente accede al autoconocimiento: desnudez y frondosidad, equivalentes en la memoria, respectivamente, a abstracción y sensorialidad. A ambas concierne la imagen del dodecaedro, con sus treinta aristas inscritas en una esfera, identificada con el pomo de marfil de un bastón en el que se apoya el anciano al que remite la cita inicial de Virgilio: si desaparece la esfera protectora, en la evocación sensorial afloran las aristas cortantes que ensangrientan la mano de quien anduvo sobre una memoria que, cuando inofensiva y esférica, resultaba privada de su poder de recuperación de la identidad pasada, y en ella del don de la escritura (pp. 20, 21, 23 y 24). El poder del color en la naturaleza como ámbito de las más profundas emociones y vía de conocimiento emocional tiene su contrapunto en la pintura (los seis colores asociados a Benozzo Gozzoli, Víttore Carpaccio, Frederic Leighton, Gentile Bellini, Jan Vermeer de Delft y Giorgione, 25).

La imaginación y los símbolos de la memoria son en Carta florentina de naturaleza líquida; la Nota preliminar señala que el libro está intuitivamente vertebrado por "las variedades y los comportamientos del agua" (p.10). Como el libro muestra en su desarrollo, se trata tanto del agua pluvial, fluvial y marina, como del agua intervenida por el arte en las fuentes y los estanques. El hito emocional primordial, el sexo, en cuanto intercambio de humores corporales, es así objeto de un "recuerdo líquido" (p. 34), y el agua es primer detonador de la memoria, no sólo en su fluir sonoro o en el rumor de unos remos al hundirse en ella o de la vegetación al recibirla (pp. 14, 17, 21, 29, 37), sino en cuanto componente del lodo y de la sangre (pp. 15, 30, 31, 35, 37, 38, 46, 47). La sequedad ("corazón sin sangre", p. 16) equivale a la resistencia al recuerdo, al instinto precautorio del olvido, y los recuerdos repudiados se confinan al fondo de un pozo (p. 36).

$\mathrm{El}$ amor transfigura a quienes lo sienten y los libera de la gravedad, de tal modo que se sienten flotar sobre el agua (pp. 18, 31, 46), tal como ocurría en Fuente de Médicis (p. 19), con recuerdo de El paseo (1917) y Sobre la ciudad (1918) de Chagall.

El libro se abre con una cita de Virgilio y otra de Monteverdi, que contraponen e interrelacionan el paisaje arcádico y el infernal. En ese arranque del libro, la primera bucólica no viene incorporada en sentido 
literal, pues los ríos que menciona resultan ahora ser dos, el del tiempo perdido y el del recobrado, en una ancianidad que el libro retiene aunque bañándola en la tristeza y la ironía; permanece, en cambio, aunque se retome y se desarrolle en otro lugar, la dimensión arcádica del intertexto virgiliano, cuando el papel de los personajes monteverdianos y su interacción resultan invertidos en el último verso del libro (p. 48).

Los dos ríos de Virgilio resultan, ya se ha dicho, reinterpretados. Uno de ellos fluye en el sentido natural del transcurso del tiempo, y así el agua (la vertical de la lluvia, la horizontal del río) es agente simbólico del paso del tiempo y del olvido, de tal modo que la imagen de una mujer que se resiste a ser olvidada se convierte en "máscara no soluble" (p. 26). Identificado con el Arno, representa el goce y las ilusiones de un presente movedizo (pp. 33, 34). Más complejo resulta el curso de la memoria recobrada (p. 44), que se manifiesta como lluvia ascensional en las fuentes (pp. 19, 20), como río de fluir también invertido (entre líneas el poder de la música de Orfeo, análogo al de la escritura, tanto como la de Anfión). En cuanto la memoria dolorida se recupera y transmuta en el poema, el agua que la fuente convierte en ornamento suele venir mezclada con sangre (p. 45), lo mismo que la sábana del encuentro amoroso pasado se identifica con la página escrita y el mantel de altar, salpicados de sangre, de lodo e implícitamente de tinta (pp. 37, 38, 45). En este punto se inserta la Santa Cecilia de Maderno; inaccesible tras su cristal en la basílica del Trastévere, representada como mártir en su mármol yacente, connotando la iconografía que le añade los atributos de la música y de la escritura, que unidas equivalen a la poesía.

El curso natural del río del presente puede invertirse, con recuperación del pasado y sus emociones, en el río del recuerdo, pero también en la medida en que las olas marinas y la marea se enfrenten a su fluir, lo detengan o lo empujen hacia atrás en la desembocadura y el estuario (p. 39). Así el Tajo en Belem (p. 22), con recuerdo del Támesis en Greenwich (Verano inglés), viene a ser el río del olvido, que puede ser detenido por la marea, o surcado por un buque que penosamente navega a contracorriente. En el estuario, las dos aguas, la fluvial y la marina, se enfrentan en su movimiento y se distinguen por su color.

La Arcadia, a la que implícitamente remitía el verso de Virgilio que abre el libro, introduce en Carta florentina el motivo del jardín o vergel, 
en tanto que espacio propio de la transitoria y engañosa felicidad pasada (p. 31), y asociado al arquetipo de la perfecta inalcanzable (pp. 15, 30) a través del mito de Dafnis y Cloe (pp. 29, 30), escenario en el que el fluir del agua sobre el cuerpo femenino desnudo conduce al descubrimiento mutuo del sexo (p. 30). La belleza de la mujer como el más perfecto de los seres se manifiesta a través de referentes acuáticos y luminosos en la elevación y descenso de las gamas de una voz de soprano, gota en el horizonte alzada hasta las nieves perpetuas, luego ensombrecida como caballo negro en la noche con jaeces de plata (p. 28); junco y flor la designan asimismo en el ámbito del jardín (pp. 26, 27). La naturaleza demoníaca y dañina de la mujer aparece en su visión como nereida (pp. 39, 40) que arrastra hasta el fondo marino a quien la ama, con el tacto de su cuerpo viscoso, antítesis de la muchacha acariciada en Taormina (p. 47), siendo en ambos casos ese tacto fuente de escritura, como lo es otra figura femenina acuática presente ya en Verano inglés, Melusina (p. 43).

\section{Conclusiones}

A la vista de lo dicho, puede llegarse a las siguientes conclusiones:

1) La visión de naturaleza y paisaje en mi obra poética, entre 1967 y 1990, es la de quien se siente segregado de la realidad y huye de ella al artificio de la cultura y el arte, siendo consciente de que en ese tránsito está abdicando de la vida. En consecuencia, aparecen en ella representados en obras de arte, como símbolos (desde la realidad o desde el imaginario cultural), y no como reflejo directo del mundo real.

2) La segunda época ofrece la recuperación de la realidad por obra del amor, con gran intensidad y presencia de los cinco sentidos. El cuerpo femenino se convierte en símbolo de vitalidad de acuerdo con el pensamiento mágico. Inicialmente, naturaleza y jardín simbolizan la vitalidad propia de la plenitud amorosa, con adaptación del motivo del lugar ameno, para terminar simbolizando soledad y muerte. Destaca en esta segunda época, por su entidad y su frecuente aparición y por ser motivo de continuidad con la primera época, la presencia del agua (río, mar, lluvia) como símbolo de la transitoriedad de la percepción sensorial, la memoria y la aniquilación. En su recurso al imaginario 
acuático, la segunda época prefigura claramente uno de los dos libros finales, Carta florentina.

3) En esos dos libros finales el paisaje está asociado a la Historia y al arte, o bien exige una lectura simbólica. La serie naturaleza-arte-poesía alcanza su mayor complejidad en la recreación de la supuesta espiritualidad de Góngora durante la concepción de la Fábula de Polifemo, entendida como una manifestación de renuncia al amor desigual que en otros poemas encarnan Moisés y el rey David, o como la renuncia final de Tiépolo a la idealización de la realidad a través del arte.

4) El universo simbólico de Carta florentina adquiere la mayor complejidad observable en este recorrido de cincuenta y un ańos: concierne al árbol y sus hojas, al sonido y al color, y sobre todo al concepto de liquidez, correspondiente de forma primordial al agua en todas sus manifestaciones, en la naturaleza y en la obra humana, pero también a la sangre, el lodo y los fluidos corporales que se vierten y se intercambian durante el encuentro sexual, del que a su vez nace la identificación de sábana, mantel de altar y página escrita. La liquidez se diversifica al asociarse al avance y retroceso, horizontal y vertical, y al afectar a la lluvia, al río, al mar y a la fuente.

5) Persiste el jardín como espacio de refugio, de conocimiento y de autoconocimiento, identificado al locus amoenus de la Arcadia, donde el personaje de Cloe encuentra su contrapunto acuático en la nereida y Melusina, espíritus, respectivamente, del agua marina y del agua dulce estancada. 